\title{
Una exploración de la relevancia de la Inteligencia Emocional en los programas educativos para los estudiantes de alta capacidad
}

\section{Al Bellamy ${ }^{1}$, David Gore ${ }^{1}$ y Judy Sturgis ${ }^{2}$}

\author{
${ }^{1}$ Departamento de Tecnología Interdisciplinar, \\ Universidad de Eastern Michigan, Ypsilanti \\ ${ }^{2}$ Departamento de Comunicación, \\ Universidad de Eastern Michigan, Ypsilanti
}

U.S.A. 


\section{Resumen}

Este trabajo examinó las relaciones entre la inteligencia emocional, locus de control, y la auto-eficacia en estudiantes de alta capacidad que participaban en un programa educativo de verano de dos semanas de duración. Los resultados mostraron correlaciones estadísticamente significativas entre estas variables. Se encontró que el género medió en estas relaciones.

Este trabajo también midió el impacto sobre la inteligencia emocional del estudiante que tuvo el diseño socio-psicológico deliberado del programa de verano. Las medias de las medidas postest de la inteligencia emocional fueron significativamente más elevadas que las medidas pretest. Los resultados de este trabajo aluden a las implicaciones teóricas y prácticas de la integración estratégica de mecanismos que fomentan el desarrollo de la inteligencia emocional en los estudiantes de alta capacidad.

Palabras clave: Inteligencia emocional, Locus de Control, Auto-eficacia, Género 